\title{
WHAT CONTRIBUTES TO TOTAL FACTOR PRODUCTIVITY GROWTH IN THE CHINESE BANKING SECTOR?
}

\author{
Ning ZHU ${ }^{1}$, Ning $\mathrm{ZHANG}^{2 *}$, Bing WANG ${ }^{2}$, Tomas BALEŽENTIS ${ }^{3}$ \\ ${ }^{1}$ School of Economics and Commerce, South China University of Technology, No. 382, \\ Outer Ring East Road, Higher Education Mega Center, Panyu District, Guangzhou, 510006, \\ Guangdong Province, P. R. China \\ ${ }^{2,3}$ School of Economics, Jinan University, No. 601, West of Huangpu Avenue, \\ Tianhe District, Guangzhou, 510632, Guangdong Province, P. R. China \\ ${ }^{3}$ Lithuanian Institute of Agrarian Economics, Kudirkos g. 18/2, LT-03105, Vilnius, Lithuania
}

Received 06 June 2017; accepted 26 November 2017

\begin{abstract}
We propose a new metafrontier, non-radial, biennial Luenberger productivity indicator to evaluate the total factor productivity growth of the Chinese banking sector, during the period of 2004-2012. The bootstrapping approach is also taken into account to introduce the statistical inference of the total factor productivity, and its components. It is found that the overall Chinese banking sector operated well with an average growth rate of $5.4 \%$, where technological progress was the driving force promoting the development of the Chinese banking sector during the earlier studied period, and efficiency gains outperformed technological progress during the later studied period. We investigated three banking groups, state-owned commercial banks and joint-stock commercial banks depending on their technological progress, but city commercial banks were dominated by efficiency gains. Regarding the productivity growth gap, the metafrontier productivity growth gap and efficiency change gap appeared to show gradual convergences, but the technological change gap maintained the width at a certain extent.
\end{abstract}

Keywords: total factor productivity, metafrontier, biennial technology, Directional distance function, data envelopment analysis, bootstrapping approach.

JEL Classification: C61, D24, G21.

\section{Introduction}

Facing the gloomy global economic downturn, China's economic growth, which was a "growth miracle", has been in a deceleration since 2007. Regarding a constant decline in labor force and capital investment in the Chinese economy, total factor productivity (TFP), which reflects both technological change and efficiency change, becomes a critical compo-

\footnotetext{
*Corresponding author. E-mail: zn928zn@hotmail.com
} 
nent to promote economic growth in China, where banking TFP is a particularly effective benchmark to evaluate and improve overall TFP.

Unfortunately, the serious global financial crisis arrived sequentially in 2008, which acted as a double-edged sword for the Chinese banking sector. On the one hand, in the context of the global economy, the global financial crisis further undermined the Chinese banking sector's development, particularly many Chinese financial institutions holding large amounts of foreign bonds probably increased economic volatility in the Chinese financial market. On the other hand, due to strict controls in China's capital account, the crisis impact to Chinese banking sector was less serious than that to the U.S. and Europe banking sectors, and thus it is a good opportunity to accelerate the development of the Chinese banking all over the world.

Hence, it is meaningful to investigate what contributes the TFP growth in the Chinese banking sector. We aim to explore the source of TFP growth in both the overall banking sector and separate bank groups, and furthermore examine their catch-up abilities of efficiency and technological changes.

Methodologically, we prefer to utilize a DEA-based non-radial and non-oriented biennial-Luenberger productivity indicator to measure TFP growth of the Chinese banking sector. Indeed, DEA is a widely applied nonparametric frontier method without any strict assumptions; the non-radial model improves the proportional changes in inputs and outputs in the Farrell-based DEA model (Tone 2001), and non-orientation is applied to analyze, simultaneously, on both cost and revenue sides of the profitability (Avkiran 2011); biennial-Luenberger productivity indicator also has some benefits like avoiding infeasibility solutions and considering undesirable outputs. Moreover, due to a heterogeneous environment and managerial choices, regarding three types of Chinese banks, we specifically incorporate the banking TFP measure into a metafrontier framework. Last but not least, since the nonparametric DEA was criticized by its deterministic form and lack of statistic inference, we additionally employed a bootstrapping approach in this current paper.

The rest of the paper is organized as follows: Section 1 reviews literatures on Chinese banking TFP growth and TFP technology. Section 2 introduces methodology. Section 3 describes data used. Section 4 empirically analyzes results and has further discussion on policy implications. The last section concludes.

\section{Literature review}

\subsection{Evaluation of TFP growth of Chinese banks}

There have been plenty of research on banking TFP growth in developed and several developing countries, but insufficient studies on that of the Chinese banking sector.

Kumbhakar and Wang (2007) applied a stochastic frontier analysis based on input distance function to analyze the impact of TFP growth to Chinese banks. Their results showed that the average TFP growth in the Chinese banking sector was positive, while, regarding two types of banks, the TFP growth of joint stock commercial banks surpassed that of stateowned commercial banks. In details, pure efficiency change did not affect TFP growth of 
both types of banks significantly. The TFP growth of state-owned commercial banks was mostly benefited by scale effect, while that of joint stock commercial banks was combined with both scale effect and technological progress.

Sufian (2009) used a Malmquist productivity index (MPI), taking off-balance sheet into account, to measure TFP growth of the Chinese banking sector. It was found that the whole banking sector had low TFP growth, whereas state-owned commercial banks and city commercial banks existed poor technological change, but benefited in scale efficiency change, while joint stock commercial banks were poor in pure technical efficiency change.

Matthews et al. (2009) used a conventional MPI with a smooth bootstrap approach to study TFP growth of the Chinese banking sector from 1997 to 2006. Apart from the two studies aforementioned, they specifically accounted for non-performing loans which has been a critical factor affecting performance of the Chinese banking sector. It is found that the overall TFP was moderate, and the TFP of joint stock commercial banks surpassed that of state-owned commercial banks. As a companion study, Matthews and Zhang (2010) used the similar approaches to further evaluate TFP growth of the Chinese banks during the period 1998-2007. They determined 5 types of models with different variables according to production and intermediation approaches. To test the contribution of deregulation, they separated the period studied into (1998-2002) and (2003-2007), and it was found that the TFP growth of first half of period (1998-2002) was better than that of the second half (2003-2007). In details, joint stock commercial banks and city commercial banks outperformed stateowned commercial banks. Investigating source of TFP growth, they revealed that efficiency improvement was driven by cost reduction, while technological progress was promoted by non-interesting income.

Chang et al. (2012) incorporated an input slack-based productivity framework into Luenberger productivity indicator $(L P I)$, and investigated the source of TFP growth by disaggregating to individual input productivity contribution. It was found that the technological change was the driving force to promote TFP growth. Regarding contribution to input productivity change, capital investment was the major source of TFP growth in the Chinese banking sector.

Zhu et al. (2015) applied a DEA-based LPI to investigate TFP growth of 25 Chinese banks over the period between 2004 and 2010. It was found that the overall Chinese banking sector performed well, where the change of return to scale in technology was the main driving force during the period studied, and pure technical efficiency change and pure technological change both were not significant, but scale efficiency change had a negative effect to TFP.

\subsection{Metafrontier framework in banking}

Earlier studies on performance evaluation generally assumed that all firms have the homogeneous technological, namely there exists only one technological frontier for all DMUs. However, due to different external factors, like heterogeneous environment, opportunity, and preference, the technology, indeed, is heterogeneous. Hayami (1969) initially proposed the conception of metaproduction function, while Hayami and Ruttan (1970) then gave a more clear interpretation of metaproduction conception. 
Comparing earlier work of Battese and Rao (2002) that assumes there simultaneously exist two data generating processes for stochastic frontier and metafrontier respectively, the standard SFA-based metafrontier approach by Battese et al. (2004) adopt to one data generating process under a given technological frontier, and implied the technological gap ratio can measure potential efficiency ratio of individual firm to whole industry. Empirically, Bos and Schmiedel (2007) compared efficiencies of more than 5000 large commercial banks in Europe between single and meta-frontiers framework, and it was found that conventional pooled form would underestimate cost and profit efficiencies. Huang et al. (2011) constructed a meta-cost frontier to evaluate performance of commercial banks across nine European countries, and it is found that quick innovations would reduce production costs and narrow technological gap between European banks. Lee and Huang (2017) established a new stochastic metafrontier Fourier flexible cost function to judge the cost efficiencies of banks in Western European countries.

Furthermore, O'Donnell et al. (2008) developed the DEA-based metafrontier approach based on distance function, and introduced the technological gap ratio as well. Subsequently, plenty of banking research using DEA-based metafrontier approach was developed. Ben Naceur et al. (2009) investigated banking efficiency of the Middle East and North Africa during financial reform period on the basis of DEA-based metafrontier framework. Kontolaimou and Kostas (2010) classified European banks as different type-specific groups according to different ownership structures, and technological gaps implied that output production provides more contributions than input use. Fu et al. (2016) used 34 Taiwanese banks and 70 Chinese banks in 2011 to empirically measure profit efficiency and its decompositions under the risk-adjusted metafrontier, and allocative inefficiency gap was found in this study.

Apart from efficiency measure, O'Donnell et al. (2008) also extended the DEA-based metafrontier approach to the field of TFP measures. Afterwards, Oh and Lee (2010) developed an alternative global metafrontier MPI. In terms of empirical banking TFP studies based on metafrontier framework, Portela and Thanassoulis (2010) applied a metafrontier MPI to assess 59 branches of a Portuguese bank. Chen and Yang (2011) employed the metafrontier MPI and its decompositions to compare banking TFP growth between China and Taiwan region. Casu et al. (2013) used both MPI and parametric Divisia index within metafrontier framework to measure TFP growth in Indian banks during 1992-2009. Zhu et al. (2015) used a metafrontier LPI to compare TFP growth of three types of banks in the Chinese banking sector. Duygun et al. (2016) applied a non-parametric metafrontier MPI to evaluate the TFP growth among UK-based trademarking and non-trademarking commercial banks.

Although there have been a rich body of studies on banking TFP growth, we indeed identify several research gaps between previous and current studies: (1) the studied periods in previous studies were mostly before 2008, which means their empirical analysis missed the meaningful period of the global financial crisis impacting the Chinese banking sector; (2) some studies considered the heterogeneity between different types of banks using a metafrontier approach to measure banking TFP, but very few studies focused on the source of potential catch-up ability; (3) several advanced technique skills, like biennial TFP framework and bootstrapping approach, are applied to improve the quality of results in this current study. 


\section{Methodology}

We treat each bank as a decision making unit (DMU) and then construct the best practice frontier with the technology with bad outputs. The assumption is there exist $K D M U s$, and each $D M U$ uses $N$ inputs $X=\left(x_{1}, \cdots, x_{N}\right) \in R_{N}^{+}$to jointly produce $M$ desirable outputs $Y=\left(y_{1}, \cdots, y_{M}\right) \in R_{M}^{+}$and $L$ undesirable outputs $B=\left(b_{1}, \cdots, b_{L}\right) \in R_{L}^{+}$. Therefore, the combination of inputs and outputs in period $t=1, \ldots, T$ is $\left(x^{k, t}, y^{k, t}, b^{k, t}\right)$. Its corresponding output sets can satisfy the byproduct axiom (null-jointness), the assumption of the compact set, and the jointly weak disposability (weak disposability of undesirable outputs and strong disposability of desirable outputs and inputs).

\subsection{Biennial Luenberger productivity indicator}

Departing from sequential technology which precludes identification of technical regress by Tulkens and Vanden Eeckaut (1995) and global technology which needs to be recomputed when a new time period is added to the data set by Pastor and Lovell (2005), in this study, we employ an alternative approach that overcomes infeasibility problem based on the biennial technology of Pastor et al. (2011). Furthermore, we propose a new approach that combines the weighted Russell directional distance model by Barros et al. (2012) and the biennial technology, which is called the biennial generalized directional distance function (BGDDF).

The BGDDF has three remarkable advantages: (1) non-radial and non-oriented inefficiency measure, which considers both input and output slacks and allows for different variations among them; (2) solving the infeasibility problem by using biennial technology; (3) a generalized inefficiency measure - the sum of all the weights to inputs and outputs equals 1 . These features make it different from other kinds of generalized directional distance function $(G D D F)$.

As with $G D D F, B G D D F$ is also an inefficiency measure. Its value can be calculated with linear programming and the greater the value, the higher the inefficiency. Here choosing $g=(y,-b,-x)$ as the directional vector, the $B G D D F$ in period $t$ can be constructed as Eq. (1).

$$
\begin{aligned}
& \vec{D}_{k}^{B}\left(x^{t}, y^{t}, b^{t} ; g^{t}\right)=\operatorname{Max} \frac{1}{N+M+L}\left(\beta_{k^{\prime} n}^{B t}+\beta_{k^{\prime} m}^{B t}+\beta_{k^{\prime} l}^{B t}\right) ; \\
\text { s.t. } & \sum_{k=1}^{K} \lambda_{k}^{t} x_{k n}^{t}+\sum_{k=1}^{K} \lambda_{k}^{t+1} x_{k n}^{t+1} \leq x_{k^{\prime} n}^{t}-\beta_{k^{\prime} n}^{B t} g_{k^{\prime} n}^{t}, n=1,2, \cdots, N ; \\
& \sum_{k=1}^{K} \lambda_{k}^{t} y_{k m}^{t}+\sum_{k=1}^{K} \lambda_{k}^{t+1} y_{k m}^{t+1} \geq y_{k^{\prime} m}^{t}+\beta_{k^{\prime} m}^{B t} g_{k^{\prime} m}^{t}, m=1,2, \cdots, M ; \\
& \sum_{k=1}^{K} \lambda_{k}^{t} b_{k l}^{t}+\sum_{k=1}^{K} \lambda_{k}^{t+1} b_{k l}^{t+1}=b_{k^{\prime} l}^{t}-\beta_{k^{\prime} l}^{B t} g_{k^{\prime} l}^{t}, l=1,2, \cdots, L ; \\
& \lambda_{k} \geq 0, \beta_{k^{\prime} n}^{B t} \geq 0, \beta_{k^{\prime} m}^{B t} \geq 0, \beta_{k^{\prime} l}^{B t} \geq 0, k=1,2, \cdots, K .
\end{aligned}
$$

In order to extend the BGDDF within Russell framework into TFP, Eq. (1) is incorporated into difference-based Luenberger productivity indicator $(L P I)$, rather than ratio-based 
Malmquist-Luenberger productivity index with undesirable outputs ${ }^{1}$, and it is defined as Eq. (2):

$$
B L P I_{t, t+1}=\vec{D}^{B}\left(x^{t}, y^{t}, b^{t} ; g\right)-\vec{D}^{B}\left(x^{t+1}, y^{t+1}, b^{t+1} ; g\right) .
$$

Based on original works of Chambers et al. (1996) and Färe et al. (1994), the BLPI can be decomposed into efficiency change (EC) and technological change (TC) in Eqs. (3)-(4)

$$
\begin{aligned}
& E C_{t, t+1}=\vec{D}^{t}\left(x^{t}, y^{t}, b^{t} ; g\right)-\vec{D}^{t+1}\left(x^{t+1}, y^{t+1}, b^{t+1} ; g\right) . \\
& T C_{t, t+1}=\left[\vec{D}^{B}\left(x^{t}, y^{t}, b^{t} ; g\right)-\vec{D}^{t}\left(x^{t}, y^{t}, b^{t} ; g\right)\right]- \\
& {\left[\vec{D}^{B}\left(x^{t+1}, y^{t+1}, b^{t+1} ; g\right)-\vec{D}^{t+1}\left(x^{t+1}, y^{t+1}, b^{t+1} ; g\right)\right] .}
\end{aligned}
$$

The $E C$ term is a measure of the catch-up effect in terms of efficiency changes for two time periods $(t, t+1)$. EC captures how close a $D M U$ comes to the frontier. Here $E C>($ or $<) 0$ means an efficiency gain (or loss). The TC term measures the frontier-shift effect of the frontier for two time periods $(t, t+1)$, representing the innovation of production during the two periods based on the frontier. Here $T C>$ (or $<$ ) 0 means technological progress (or decline).

\subsection{Metafrontier approach}

Suppose there are $H$ groups with some technological heterogeneities. In this case, the resources, technologies and other specific environmental constraints may prevent $D M U$ in specific groups from accessing other groups' generation technologies. Following Battese et al. (2004), we define the group-frontier technology of group $h$ as $P^{h}=\{(x, y, b): x$ can produce $(y, b)\}$, where $h=1,2, \ldots, H$. Assume that $P^{h}(x)$ is specified as the production technology. Then, we can define the GDDF for group $h$ as:

$$
\vec{D}^{h}\left(x, y, b ; g_{x}, g_{y},-g_{b}\right)=\sup \left\{\beta:\left(x-\beta g_{x}, y+\beta g_{y}, b-\beta g_{b}\right) \in P^{h}\right\} .
$$

Unlike the group-frontier technology, the metafrontier technology is constructed from all observations for whole groups by enveloping all group-frontier technologies. Formally, it is $P_{t}^{M}=\left\{P_{t}^{1} \cup P_{t}^{2} \cup \ldots \cup P_{t}^{H}\right\}$. Here, we can also formulate a directional distance function based on a metafrontier technology as follows:

$$
\vec{D}^{M}\left(x, y, b ; g_{x}, g_{y},-g_{b}\right)=\sup \left\{\beta:\left(x-\beta g_{x}, y+\beta g_{y}, b-\beta g_{b}\right) \in P_{t}^{M}\right\} .
$$

For each group $h$, we have the following constraints Eq. 7 , which indicates that the metafrontier is always beyond each group-frontier, or at least overlaps with a specific groupfrontier.

$$
\vec{D}^{M}\left(x, y, b ; g_{x}, g_{y},-g_{b}\right) \geq \vec{D}^{h}\left(x, y, b ; g_{x}, g_{y},-g_{b}\right) .
$$

By considering the group- and metafrontier concept in LPI, we define the difference between metafroniter Luenberger productivity indicator $(M L P I)$ and group-frontier Luenberger productivity indicator $(G L P I)$ as the metafrontier productivity growth gap indicator $(M P G G I)$

\footnotetext{
${ }^{1}$ Some studies showed that the Luemberger productivity indicator is more robust than the Malmquist productivity index (Chang et al. 2012; Fujii et al. 2014).
} 


$$
M P G G I_{t, t+1}=M L P I_{t, t+1}-G L P I_{t, t+1} \text {. }
$$

MPGGI is a measure of changes in the productivity growth gap between the groupfrontier and the metafrontier during two periods. $M P G G I>($ or $<$ ) 0 indicates a decrease (increase) in the productivity growth gap between a specific group and the metafrontier.

Similar to Eqs (3)-(4), MLPI can also be divided into metafrontier efficiency change (MEC) and metafrontier technological change (MTC) as follows, and so is the GLPI:

$$
\begin{aligned}
& M L P I_{t, t+1}=M E C_{t, t+1}+M T C_{t, t+1} \\
& G L P I_{t, t+1}=G E C_{t, t+1}+G T C_{t, t+1} .
\end{aligned}
$$

By combing Eqs (9)-(10), we derive the following decompositions:

$$
\begin{aligned}
& M P G G I_{t, t+1}=(\underbrace{M E C_{t, t+1}+M T C_{t, t+1}}_{M L P I_{t, t+1}})-(\underbrace{G E C_{t, t+1}+G T C_{t, t+1}}_{G L P I_{t, t+1}})= \\
& (\underbrace{M E C_{t, t+1}-G E C_{t, t+1}}_{E C G_{t, t+1}})+(\underbrace{M T C_{t, t+1}-G T C_{t, t+1}}_{T C G_{t, t+1}}) .
\end{aligned}
$$

From Eq. (12), it is found the MPGGI can be further decomposed into the efficiency change gap (ECG), the technological change gap (TCG). ECG measures the efficiency change gap between group-frontier and metafrontier to capture the pure catch-up gap change; it is identical to the pure technological catch-up (PTCU) in Chen and Yang (2011). ECG > (or <) 0 means a shrinkage (increase) of the technological gap in terms of pure catch-up. On the other hand, TCG measures the velocity of frontier-shift between the group-frontier and the metafrontier that captures the innovation gap change. TCG is similar to the frontier catchup (FCU) component in Chen and Yang (2011). TCG $>($ or $<) 0$ means the group frontier shift is faster (slower) than the metafrontier shift, indicating the reduction (enhancement) of innovation gap.

By rearranging Eq. (11), the MLPI can be decomposed in the following way:

$$
M L P I_{t, t+1}=G E C_{t, t+1}+G T C_{t, t+1}+E C G_{t, t+1}+T C G_{t, t+1} .
$$

\subsection{Bootstrapping approach}

Because metafrontier biennial Luenberger productivity indicator $(M B L P I)$ is derived from the $B G D D F$ that are calculated based on the estimate of the true production frontier, it will be subject to uncertainties due to the sampling variation of the obtained production frontier. Therefore, it is meaningful to introduce the statistical inference for MBLPI with respect to the sampling variation by bootstrapping the indicator.

We use the algorithm developed by Simar and Wilson (1998) to bootstrap MBLPI. The simplified process for bootstrapping $M B L P I$ is summarized as follows:

1) Calculate $\operatorname{MBLPI}_{i}(t, s)$ for $i=1,2, \cdots, N$ by using Eqs (2)-(3).

2) Based on the bivariate kernel density estimator and the reflection method suggested by Simar and Wilson (1998), we generate two pseudo datasets $\left\{\left(x_{i}^{t}, y_{i}^{t}, b_{i}^{t^{*}}\right), i=1,2, \cdots, N\right\}$ and $\left\{\left(x_{i}^{s}, y_{i}^{s}, b_{i}^{s^{*}}\right), i=1,2, \cdots, N\right\}$ with the normal reference rule of bandwidth. 
3) Compute the bootstrap estimate of $M_{B L P I}^{*}(t, s)$ of $M B L P I_{i}(t, s)$ for $i=1,2, \cdots, N$ by solving Eqs (2)-(3) using the production technologies constructed from the pseudo datasets obtained in Step 2.

4) Repeat Steps 2-3 B times $(B=2000)$ to provide bootstrapped estimates $\left\{M B L P I_{i, b}^{*}(t, s), b=1,2, \cdots, B\right\}$ for $i=1,2, \cdots, N$.

5) From sorting the bootstrapped B estimates of $M B L P I$, by setting the preferred percentiles (1\%,5\% and 10\%), we can construct confidence intervals of MBLPI.

For a specific $D M U$, if zero does not fall between the confidence intervals of MBLPI, the improvement or deterioration in the TFP of this DMU is significantly different from zero, under the desired significance level. Similarly, we can also use the estimates to test the significance of the contributing components of MBLPI, such as EC, TC, and MPGGI.

\section{Data used}

There are 270 observations covering 30 Chinese commercial banks including 4 state-owned commercial banks (SOCBs), 10 joint stock commercial banks (JSCBs), and 16 city commercial banks (CCBs), over the period 2004-2012. All data are from Bankscope database, and price is constant in 2004 .

Berger and Humphrey (1997) argued that both the production and the intermediation approaches cannot fully capture the role of financial sector, and the profit-oriented approach by Drake et al. (2006) became a more welcome variable selection in evaluating banking performance, due to both decreasing cost and increasing revenue are considered simultaneously (Drake et al. 2006; Pasiouras 2008; Avkiran 2011; Zhu et al. 2015). A typical profit-oriented approach treats cost component, like interest expense and non-interest expense as input, while treats revenue component, like interest income and non-interesting income as output.

In general, we employ the profit-oriented approach to determine input and output variables, but we additionally consider some more specific variables that correspond to "real life" of the Chinese banking sector.

First, as mentioned above, scale expansion is a critical factor to increase banking profit in China (Kumbhakar, Wang 2007), and fixed assets, as the proxy of scale expansion, is a necessary variable in current study. Second, comparing conventional interest income, performing loans, as a main source of interest income, reflects banking profitability, safety, and liquidity, which means performing loans convey more information than interest income, and thus the performing loans, interpreted as a desirable output, is employed to replace interest income. Last but not least, non-performing loans is an acknowledged component during the Chinese banking sector reform, and it has been a common accepted undesirable output on evaluating the performance of the Chinese banking sector.

Finally, we choose three inputs, including interest expense (IE), non-interest expense $(N I E)$, and fixed assets $(F A)$, two desirable outputs, including performing loans $(P L)$ and noninterest income $(N I I)$, and one undesirable output, including non-performing loans $(N P L)$, in this study as follows. 
Table 1 is a descriptive statistics of input and output variables of three types of banks during 2004-2012. It is straightforwardly found that, (1) absolute gaps among various resources of the three types of banks are obvious, where SOCBs are with the largest share, but CCBs as the youngest banking group maintain a faster growth; (2) the increase of $F A$ in $C C B$ s $(16 \%)$ is fast than that of SOCBs (6\%) and JSCBs (9\%); (3) NII has the fastest growth rate in all variables for three types of banks, where the rates of CCBs (88\%) and JSCBs (55\%) obviously surpass that of SOCBs (35\%); (4) SOCBs have the largest magnitude of positive effect in reducing NPLs $(-13 \%)$ than the JSCBs $(-2 \%)$ and CCBs $(2 \%)$, and NPLs have a rebound after 2011 due to economic slowdown in China.

Table 1. Descriptive statistics

\begin{tabular}{|c|c|c|c|c|c|c|c|}
\hline \multirow{2}{*}{ Variable } & \multicolumn{2}{|c|}{2004} & \multicolumn{2}{|c|}{2008} & \multicolumn{2}{|c|}{2012} & \multirow{2}{*}{$\begin{array}{l}\text { Average } \\
\text { growth }\end{array}$} \\
\hline & Mean & S.D. & Mean & S.D. & Mean & S.D. & \\
\hline IE(SOCB) & 51635 & 12406 & 120985 & 22846 & 201916 & 26282 & 0.20 \\
\hline IE(JSCB) & 6770 & 2653 & 21507 & 9225 & 50434 & 21080 & 0.31 \\
\hline $\mathrm{IE}(\mathrm{CCB})$ & 800 & 749 & 2084 & 1924 & 7191 & 6479 & 0.42 \\
\hline NIE(SOCB) & 49648 & 1052 & 75888 & 6853 & 114230 & 10692 & 0.12 \\
\hline NIE(JSCB) & 5425 & 3826 & 11032 & 5701 & 20465 & 8992 & 0.20 \\
\hline NIE(CCB) & 499 & 555 & 913 & 776 & 2115 & 1355 & 0.24 \\
\hline $\mathrm{FA}(\mathrm{SOCB})$ & 67469 & 13255 & 75621 & 14619 & 106451 & 12181 & 0.06 \\
\hline FA(JSCB) & 6529 & 6289 & 7577 & 6644 & 11277 & 9245 & 0.09 \\
\hline $\mathrm{FA}(\mathrm{CCB})$ & 656 & 446 & 818 & 614 & 1726 & 1273 & 0.16 \\
\hline $\mathrm{PL}(\mathrm{SOCB})$ & 2313355 & 542659 & 3122770 & 554975 & 5651572 & 819545 & 0.12 \\
\hline PL(JSCB) & 277982 & 144860 & 530159 & 270207 & 1056638 & 540043 & 0.18 \\
\hline $\mathrm{PL}(\mathrm{CCB})$ & 24632 & 31566 & 47659 & 45000 & 110043 & 97458 & 0.24 \\
\hline NII(SOCB) & 13547 & 5907 & 35684 & 14504 & 79015 & 10064 & 0.35 \\
\hline NII(JSCB) & 909 & 827 & 3753 & 2846 & 11349 & 6772 & 0.55 \\
\hline NII(CCB) & 126 & 166 & 336 & 270 & 765 & 625 & 0.88 \\
\hline NPL(SOCB) & 418627 & 371382 & 90104 & 19364 & 59055 & 6564 & -0.13 \\
\hline NPL(JSCB) & 15507 & 11225 & 8257 & 5393 & 8317 & 4862 & -0.02 \\
\hline NPL(CCB) & 1899 & 2099 & 825 & 909 & 806 & 680 & 0.02 \\
\hline
\end{tabular}

Note: S.D. - standard deviation (source: The data are from Bankscope database).

\section{Empirical analysis}

This section first analyzes the TFP growth and its decompositions in the overall Chinese banking sector. It then similarly investigates the differences among the three types of banks, including $S O C B$, JSCB, and CCB. Moreover, the TFP growth gap is studied as well. We also specifically highlight the scale effect to the TFP growth. Finally, according to empirical results, a further discussion is supplemented. 


\subsection{TFP growth at the industry level}

Table 2 present the overall TFP growth and its decompositions at the Chinese banking sector level. On the whole, the average MBLPI of the Chinese banking sector, during the studied period, is $5.4 \%$, where $M T C$ represents the innovation effect with the average growth rate of $4.4 \%$, while the other component, $M E C$, represents a catch-up effect with an average growth rate of $1 \%$, which is mentioned above and is consist with the results of many relevant studies, like Matthews and Zhang (2010) and Chang et al. (2012). This technological progress, but not efficiency gain, has been the driving force of the Chinese banking sector development. To sum up, in terms of TFP growth pattern, with the exception of several banks with inconspicuously negative values, $83.3 \%$ (25/30) banks operate with positive average $M B L P I$, $76.7 \%$ (23/30) with a positive average MEC, and $83.3 \%$ (25/30) with a positive average MTC.

Table 2. Overall TFP growth and its decompositions

\begin{tabular}{|l|c|c|c|c|c|c|c|c|c|}
\hline \multicolumn{1}{|c|}{ Bank } & Group & MBLPI & EC & TC & Bank & Group & MBLPI & EC & TC \\
\hline ICBC & S & 0.067 & 0.041 & 0.026 & BNJ & C & 0.075 & 0.027 & 0.048 \\
\hline CCB & S & 0.068 & 0.023 & 0.046 & BDG & C & 0.050 & 0.005 & 0.045 \\
\hline BC & S & 0.040 & 0.020 & 0.020 & BDL & C & 0.024 & -0.003 & 0.026 \\
\hline ABC & S & 0.043 & 0.029 & 0.014 & BHB & C & -0.036 & 0.000 & -0.036 \\
\hline BCM & J & 0.062 & 0.033 & 0.028 & BHEB & C & -0.012 & -0.074 & 0.062 \\
\hline CEB & J & 0.139 & 0.029 & 0.110 & BHK & C & 0.001 & 0.068 & -0.068 \\
\hline CITIC & J & 0.058 & 0.055 & 0.004 & BHZ & C & 0.083 & -0.006 & 0.089 \\
\hline CMB & J & 0.046 & 0.000 & 0.046 & BJZ & C & -0.003 & -0.003 & 0.000 \\
\hline CMSB & J & 0.052 & 0.000 & 0.052 & BQD & C & 0.034 & -0.058 & 0.092 \\
\hline GDDB & J & 0.050 & -0.039 & 0.088 & BSH & C & 0.028 & 0.000 & 0.028 \\
\hline HXB & J & 0.055 & 0.015 & 0.041 & BTJ & C & 0.069 & 0.050 & 0.019 \\
\hline IB & J & 0.276 & 0.000 & 0.276 & BWZ & C & -0.045 & 0.024 & -0.070 \\
\hline SPDB & J & 0.040 & 0.000 & 0.040 & BZS & C & 0.086 & 0.000 & 0.086 \\
\hline SZDB & J & 0.228 & 0.080 & 0.148 & EB & C & -0.010 & 0.047 & -0.056 \\
\hline BBJ & C & 0.046 & 0.000 & 0.046 & Mean & & 0.054 & 0.010 & 0.044 \\
\hline BNB & C & 0.015 & -0.051 & 0.066 & & & & & \\
\hline
\end{tabular}

Note: S represents SOCB, J represents JSCB, C represents CCB.

For the individual bank, IB in the JSCB shows the highest average MBLPI (27.6\%), whereas BWZ in the CCB shows the lowest average MBLPI (-4.5\%). Dividing MBLPI into MEC and $M T C$, it is found that, SZDB (8\%) in the JSCB and BHEB (7.4\%) in the CCB have the highest and lowest average $M E C$ s respectively, while the highest average $M T C$ is assigned to IB $(27.6 \%)$ in the JSCB, and the lowest average is BWZ (-7\%) in the CCB.

To investigate the change of MBLPI, MEC, and MTC of the overall Chinese banking sector during the period over 2004-2012, basically, the MBLPI shows a significant downturn during the studied period, except a sudden uptrend which occurred during 2008-2009 from $-1.6 \%$ to $11.7 \%$. MEC had a similar change pattern like MBLPI until 2010, and it 
appears to rebound from $-2.3 \%$ to $6.6 \%$ during the later period (2010-2012). Moreover, MTC almost performs a drop trend except a slight rise during 2007-2009, but on the whole, $M T C$ outperforms $M E C$, and very much before 2011. Indeed, MTC was the main driving force to promote the TFP growth in the Chinese banking sector during the earlier period (2004-2010), but MEC surpassed MTC during the later period (2010-2012).

A noteworthy point here is that there was an unusual increase at different degrees for all MBLPI, MEC, and MTC during 2008-2009. According to available data in Table 1, investigating banking operations during the period of 2008-2009 against the period 2007-2008, it is found that NPLs decreased by $2.7 \%$, and $P L$ increased by $24 \%$. A potential explanation for that is, although the global financial crisis undermined the development of the Chinese banking sector, for instance, the NII during 2008-2009 decreased by $57.3 \%$ against that during 2007-2008, various counter-cyclical regulatory measures and macroeconomic adjustments effectively minimized the negative crisis effect in China. Due to a specifically strengthened risk management system during 2008-2009, the NPLs decreased, and the PL increased, to improve TFP growth. Moreover, in order to stimulate real economic growth in China, lower interest rates, based on easy monetary policy, made credit operations rapidly increase, which is an important component to improve performance of the Chinese banking sector.

Furthermore, the bootstrap results based on Simar and Wilson (1998) present that about $70 \%$ (169/240) MBLPIs are significant at 10\% level, where 64\% (153/240) MBLPIs are significant at $1 \%$ level. After investigating the statistic inferences in the two components, although MTC surpasses MEC according to indicator values, there is only 29\% (70/240) significances at $10 \%$ level in MTC, which is less than that in MEC with 38\% (91/240) ones at $10 \%$ level. In addition, considering the significant changes, particularly after 2010, the proportion of significances at $10 \%$ level in MEC (17/60) obviously surpass that in MTC (9/60), which further confirms that efficiency gains play a critical role in promoting the development of the Chinese banking sector during the later period.

\subsection{TFP growth at the group level}

\subsubsection{SOCB group}

Figure 1 illustrates changes of GBLPI, GEC, and GTC in the SOCB group during the period over 2004-2012. Analogous to the results at industrial level, the GBLPI, on the whole, shows a decline, but a strong rebound from $-6.3 \%$ to $20.5 \%$ during $2008-2009$. GEC has a similar trend like GBLPI, but its range ability is smaller. In terms of GTC, there was an increasing trend until 2009, which then starts to fall below zero in 2012. It is obviously found that GTC, whose average growth rate is $3.6 \%$, is dominant in promoting TFP growth in SOCBs, but the average growth rate of GEC is only $0.6 \%$. Regarding the statistical inference, the proportion of significances at $10 \%$ level in SOCBs is small, and the proportion of significance in GTC $(10 / 32)$ is greater than that in GEC (6/32).

\subsubsection{JSCB group}

Figure 2 illustrates changes of GBLPI, GEC, and GTC in the JSCB group during the period over 2004-2012. Nearly all of these TFP indicators are above zero, implying the overall JSCB group performed well during the period studied. Moreover, the trend of GTC (which has an 
average growth rate of $6.8 \%$ ) is much closer to that of the GBLPI, which means the largest contribution to promoting TFP growth in the JSCB group comes from technological progress, while GEC (with an average growth rate of $0.8 \%$ ) slightly fluctuates around the zero, which means the efficiency gain has an insignificant effect to the JSCB group development. However, during the last period (2011-2012), GTC fell behind GEC. Investigating bootstrap results, analogous with the $S O C B$ group, show the proportion of significances at $10 \%$ level in JSCB's GTC (38/80) is beyond that in GEC (24/80), and specifically, all JSCB's GTCs are significant at $10 \%$ level during 2008-2009.

\subsubsection{CCB group}

Figure 3 illustrates changes of GBLPI, GEC, and GTC in the CCB group that occurred in the period 2004-2012. During the period of 2004-2010, there are various " $M$ " sharps for the GBLPI and its components, and all three of them performed closely. However, after 2010, there are significantly divergent trends, where GEC changed with positive growth, but GTC dropped seriously with GBLPI. In general, the dislike source of TFP growth in SOCB and $J S C B, G E C$ whose average growth rate is $2.7 \%$ plays the main driving force in the CCB group, whereas the average GTC is $-0.9 \%$. In terms of bootstrap results, the proportion of significances at $10 \%$ level in GEC (62/128) is similar that in GTC (64/128).

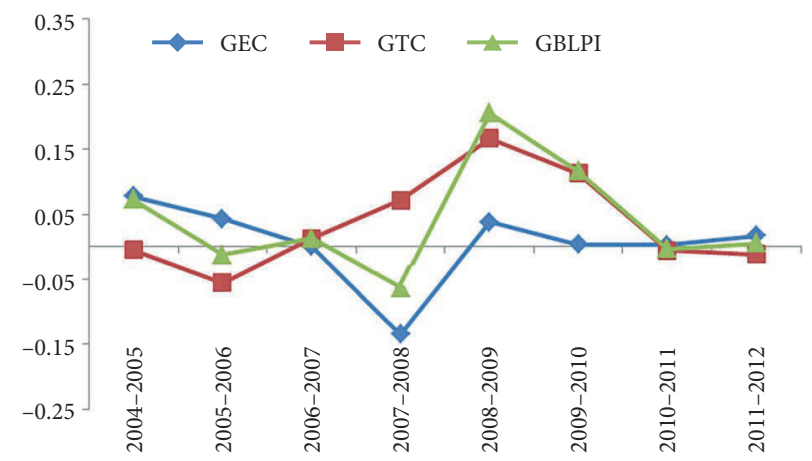

Figure 1. Trends in GBLPI, GEC and GTC of the SOCB

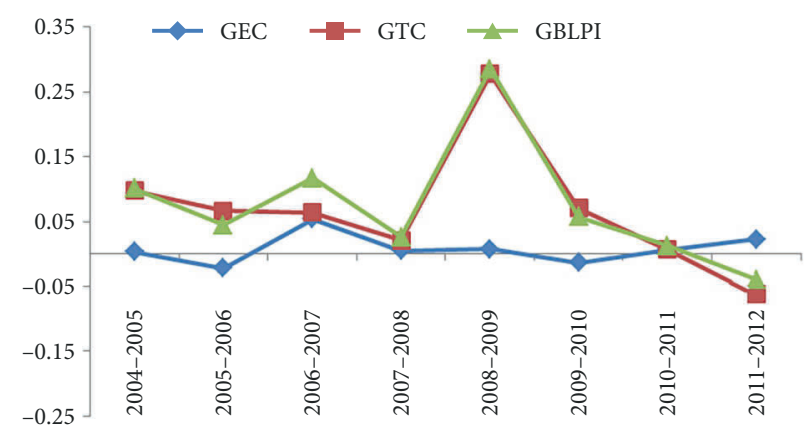

Figure 2. Trends in GBLPI, GEC and GTC of the JSCB 


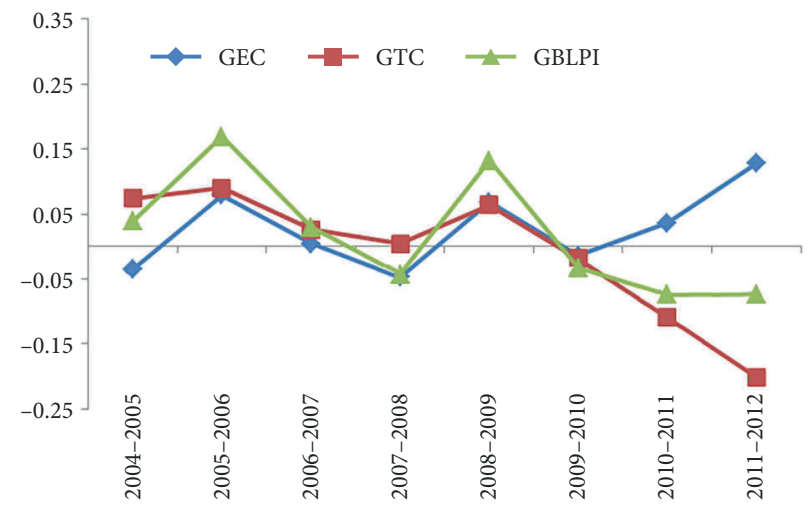

Figure 3. Trends in BGLPI, GEC and GTC of the CCB

\subsubsection{Comparison}

Comparing the GBLPI, GEC, and GTC of the three types of banks, it is found that, on average, JSCB group (7.6\%) performed the best in GBLPI, and the GBLPI of SOCB is $4.1 \%$, and that of $C C B$ is $1.8 \%$ which is obviously below those of the other two groups. In terms of the GTC, there is a similar pattern, like GBLPI, implying JSCB outperforms and SOCB becomes closer to $J S C B$, but $C C B$ shows a more serious decline as time passes. However, $C C B$ stood out in GTC among the three groups; JSCB is not so impressive and $S O C B$ plays a loser in this component.

\subsection{TFP growth gap and its components}

The average MPGGI of the Chinese banking sector is $1.4 \%$, indicating the average decrease rate in TFP growth gap between potential (metafrontier) and actual (groupfrontier) is 1.4\%. Investigating the two components divided, the average contribution of ECG, representing the catch-up gap change, is $-0.8 \%$, and that of TCG, representing the innovation gap change, is $2.1 \%$. This means that in terms of the Chinese banking sector the technological innovation gap has become narrower, however there was a slight expansion in the catch-up gap. Comparing the three types of banks, the average MPGGI in the JSCB group is larger by $2.5 \%$ than that of the $S O C B(1.3 \%)$ and $C C B(0.7 \%)$, but comparing sources of TFP growth gap, SOCB and $C C B$ reduced the most gaps in ECG by $2.2 \%$ and TCG by $3.3 \%$ respectively, beyond JSCB.

In addition, concerning the average MPGGI for an individual bank, it illustrates that IB, in the JSCB group, occupies the highest MPGGI with an average growth rate of $15.8 \%$, and $\mathrm{EB}$ in the $C C B$ group gets the lowest one with $-16.8 \%$. Meanwhile, it is also the same results for IB and EB with the highest (15.8\%) and lowest (-12\%) values in TCG respectively. Moreover, ICBC in the SOCB group outperforms in ECG with $4.1 \%$, and BJZ in the CCB group operates the worst with $-8.5 \%$. Investigating the TFP growth gap pattern, the proportion of positive results are 60\% (18/30) for MPGGI, 66.7\% (20/30) for ECG, and 56.7\% (17/30) for TCG respectively.

Furthermore, we investigated the dynamic TFP growth gap and its decompositions in Figures 4-6. 


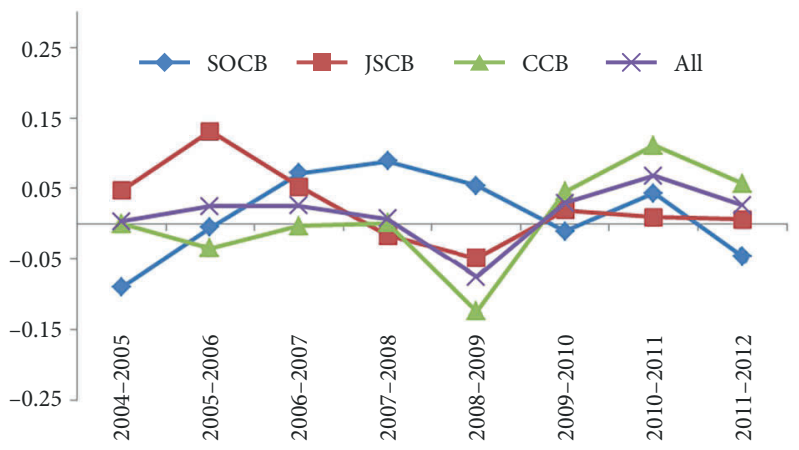

Figure 4. MPGGI change: 2004-2012

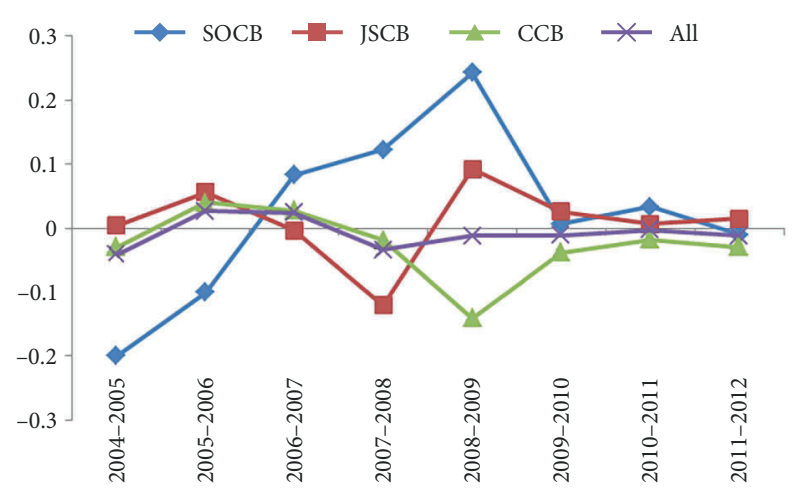

Figure 5. ECG change: 2004-2012

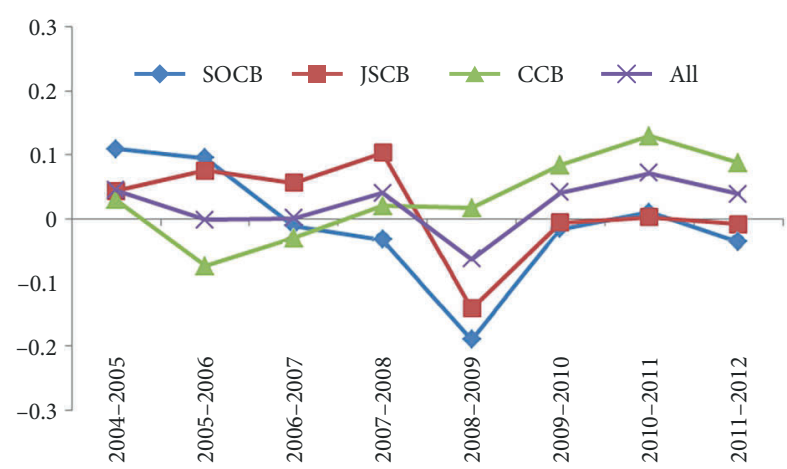

Figure 6. TCG change: 2004-2012

In Figure 4, it is found that MPGGI change indicating the overall TFP growth gap change, in the Chinese banking sector, is mostly above zero. JSCB decreased the TFP growth gap faster at the beginning of the studied period, but it was surpassed by SOCB during 2006-2009 and CCB during 2009-2012 gradually. 
Figure 5 presents that the ECG in the Chinese banking sector fluctuates within a small range. However, SOCB shows an inverted " $U$ " sharp in ECG, particularly exceeding JSCB and $C C B$ during 2007-2009, and ECG in CCB is mostly below zero. It presents that, although $C C B$ has the highest GEC as mentioned above, it has a weaker catch-up ability than $S O C B$, whose GEC is lower. The explanation is that the room for improvement becomes difficult to be further expanded on, if the bank (like $C C B$ ) has been at a higher level. However, $S O C B$ has poorer efficiency gains, so it is more probable to further improve its catch-up ability in its current state.

The TCG change during the period studied is illustrated in Figure 6. Indeed, the Chinese banking sector has a moderate change in TCG. SOCB has a similar change pattern as, but below JSCB in TCG. However, CCB shows an increase trend, and it is far ahead of SOCB and JSCB, after 2009 particularly. This is the same reason for ECG and how it can be used to explain why $C C B$ has a lower GTC, but higher TCG during the period studied.

\subsection{Scale efficiency change}

Remarkably, Kumbhakar and Wang (2007) and Zhu et al. (2015) highlight the importance of scale efficiency change (SEC) in the Chinese banking sector, and thus it is necessary to investigate the SEC here as well. Departing from conventional TFP decomposition with SEC by Färe et al. (1994), the modified version by Ray and Desli (1997) is more appropriate (Casu et al. 2013). As a result, we further decompose MBLPI, GMLPI and MPGGI with SEC component according to Ray and Desli (1997)'s decomposition.

The SEC term evaluates the scale effect of the CRS and VRS frontiers for two time periods $(t, t+1)$. SEC represents how close a $D M U$ is from moving to most productive scale size. Here SEC > (or $<$ ) 0 means scale gains (or loss). Indeed, the average SEC in the Chinese banking sector is $2 \%$, less than average pure TC of $2.2 \%$, but more than the average EC of $1.2 \%$, and the bootstrap results present there are 99/240 significances at $10 \%$ lever, implying that it is a relatively robust measure to evaluate the $S E C$ in the Chinese banking sector.

Figure 7 illustrates SEC trends of SOCB, JSCB, and CCB during 2004-2012. It is found that, $S O C B$ shows a rough increasing trend of $S E C$, while both $J S C B$ and $C C B$ have decrease changes in SEC. Indeed, on average, SOCB has the highest group SEC of $4.6 \%$, and JSCB and $C C B$ gain the SECs of $3.3 \%$ and 3.5, respectively. A potential explanation is that scale expansion was an important factor to increase banking profitability in China, due to its special financial environment (Zhu et al. 2015), but it is a double-edged sword which has been closely concerned with substantial banking development since 2003, where SOCB streamlined the overstaffed organization, and small-medium commercial banks, particularly $C C B$, expanded rapidly. However, over-expansion caused $C C B$, whose FA growth rate is the fastest as described in Table 1, to decrease the SEC gradually. Moreover, due to an effectively shrinking bloated body under the constraint of $S O C B$ reform requirement, $S O C B$ outperformed in the SEC component.

The SEC gap (SECG) measures the scale efficiency change gap, between group-frontier and metafrontier, to move to productive scale size. SECG $>($ or $<) 0$ means the distance between $C R S$ and VRS frontier sharps, in the group frontier, are closer (farther) than that in 


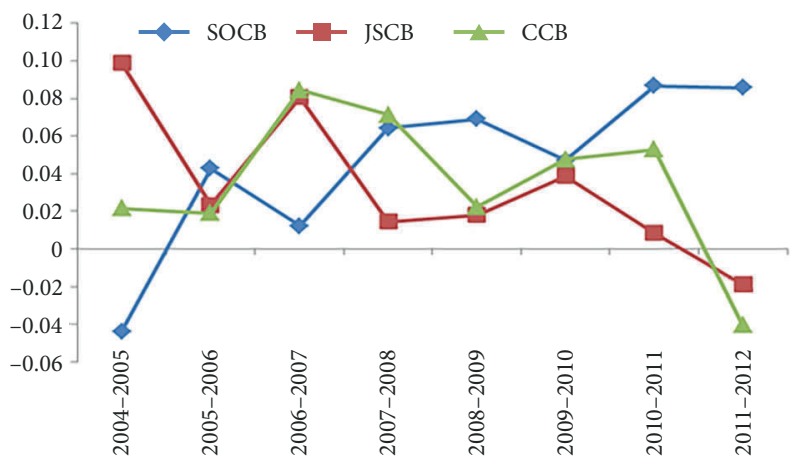

Figure 7. SEC trends of three types of banks: 2004-2012

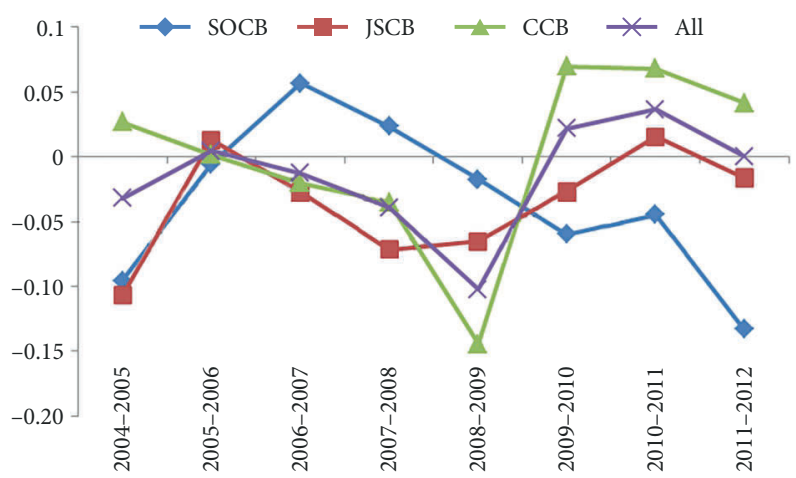

Figure 8. SEC gap change

the metafrontier. In terms of the SECG change of the three types of banks, and all banks in Figure 8, all banks show a rough " $M$ " sharp, where SECG, during 2008-2009, is at the bottom. Comparing the three types of banks, SOCB shows a consistent falling rate after 2007, while $J S C B$ and $C C B$ have similar trends, but with different change ranges.

\subsection{Discussions}

According to the empirical results mentioned above, it is meaningful to discuss potential policy implications due to overall TFP growth, and its components, in the Chinese banking sector, particularly the three types of banks showing different responses in terms of Chinese banking reform.

Firstly, in terms of technological change, the average $M T C$ is higher than $M E C$, but it shows a downturn as time passes. As a matter of fact, in addition to the factor inputs (like updating physical equipments), monetary credit policy and regulations can also more substantially impact frontier movement as well. As we all know, the constant physical equipment updates in the Chinese banking sector are effective, particularly after Chinese banking reform since 2003. Chinese commercial banks have widely adapted to applying advanced 
technology, through their computer networks, to improve profitability, but the MTC still presents an obvious falling trend during the earlier period 2004-2008, which means macroeconomic policy is a crucial factor that impacts MTC. For instance, in order to adapt to the economic slowdown before 2008, tight monetary policy and strict capital regulations slowed loan growth rate, and it thus shows a drop in MTC during 2006-2008. Comparing the three types of banks, to smaller (local) businesses in $C C B$, than those in SOCB and JSCB, we can see macroeconomic policy effect to $C C B$ is less significant than the other two types of banks. However, technological regression still existed during 2009-2012 when macroeconomic policy controls became regular. This probably attributes to homogeneous profit models among the Chinese banking sector, namely, the lack of substantially new financial innovations causing technological regression. In brief, it is important to regularly maintain the stable cooperation between a macroeconomic environment and monetary policy, but not to implement sudden decisions, which cause several conflicts; moreover, it is necessary to stimulate banking competitions to explore newer financial businesses, by favorable policies, for instance, continuing to increase the IT platform investment to achieve technological progress and innovation effectively.

In terms of efficiency change, although $M E C$ is behind $M T C$ on average, it improves significantly after 2010, which is partly due to perfecting the internal control mechanism according to new regulatory standard based on the Basel III. Moreover, Chinese banking reform since 2003, like financial restructure, introduced qualified foreign institutions' investment, and initial public offering, substantially improved efficiency gains as well. In particular, in order to survive and develop within the overall environment, such as the Chinese banking sector that has fully opened up to the world, and macroeconomics that have slowed in China, all Chinese commercial banks have to improve their efficiency gains substantially as soon as possible. Indeed, $C C B$, as a younger and smaller banking group than $S O C B$ and $J S C B$, outperformed in this component. Therefore, in order to maintain positive efficiency gains, it is necessary to push ahead with reforming measures in the Chinese banking sector, like reducing government intervention, increasing risk management, and optimizing management structure, to control the new NPLs in a reasonable range and improve efficiency gains further. Moreover, it is an appropriate way to improve efficiency gains by increasing scale efficiency, so that facing the bloated body left over by China's history, SOCB needs to effectively reduce redundant branches and employees to improve banking efficiency. Meanwhile, $J S C B$ and $C C B$ should control their scale expansion rate that is associated with their actual conditions as well.

Concerning the TFP growth gap, indeed, the ECGs of $S O C B$, JSCB, and CCB became insignificant after 2010, but the TCGs are still narrowing in 2012. As mentioned above on technological changes, with exception of updating physical equipments constantly, it is more important to reasonably adjust macroeconomic regulations and monetary policy to cultivate a fair and competitive environment for different types of banks; and encourage commercial banks to innovate new financial productions. On the other hand, optimizing banking structure and improving risk management will further lead to a narrow efficiency change gap. 


\section{Conclusions}

In this paper, we incorporate a new non-radial biennial Luenberger productivity indicator, within the metafrontier framework, to investigate TFP growth of the Chinese banking sector and three banking groups during the period over 2004-2012. Regarding TFP growth at an industry level, the TFP growth on average is 5.4\%, implying that the overall Chinese banking sector operated well which is also confirmed by bootstrap results, and technological progress is the driving force in promoting the development of the Chinese banking sector. However, considering dynamic trends, efficiency gains played a critical role after 2010. Comparing the three types of banks at the group level, JSCB and SOCB surpass $C C B$ significantly in overall TFP growth. Regarding two individual components, $C C B$ shows a serious decline behind $S O C B$ and $J S C B$ in efficiency change, but it is inverted in the technological change. Moreover, $S E C$ is positive for the Chinese banking sector and the three types of banks, where SOCB is the most notable beneficiary.

We also investigated TFP the growth gap between the metafrontier and the group frontier. There is an average $1.4 \%$ rate of reducing gap from group frontier against metafrontier, where TCG becomes narrowing, whereas ECG still has a significant gap. To have a TFP convergence as soon as possible, good cooperation between the macroeconomic environment and monetary policy is essential.

\section{Acknowledgements}

The authors gratefully acknowledge financial supports from the National Natural Science Foundation of China (71703040), the Humanities and Social Research Project of Ministry of Education of China (17YJC790215, 17JZD013), the Fundamental Research Funds for the Central Universities (2017BQ010), and the Philosophy and Social Science Project of Guangdong Province (GD15XYJ19).

\section{References}

Avkiran, N. K. 2011. Association of DEA super-efficiency estimates with financial ratios: investigating the case for Chinese banks, Omega 39(3): 323-334. https://doi.org/10.1016/j.omega.2010.08.001

Barros, C. P.; Managi, S.; Matosek, R. 2012. The technical efficiency of Japanese banks: non-radial directional performance measurement with undesirable output, Omega 40(1): 1-8. https://doi.org/10.1016/j.omega.2011.02.005

Battese, G. E.; Rao, D. S. P. 2002. Technology potential, efficiency and a stochastic metafrontier function, International Journal of Business and Economics 1(2): 87-93.

Battese, G. E.; Rao, D. S. P.; O’Donnell, C. J. 2004. A metafrontier production function for estimation of technical efficiencies and technology gaps for firms operating under different technologies, Journal of Productivity Analysis 21(1): 91-103. https://doi.org/10.1023/B:PROD.0000012454.06094.29

Ben Neceur, S.; Ben-Khedhiri, H.; Casu, B. 2009. What drives the efficiency of selected MENA banks? A meta-frontier analysis, No. 499, Working Papers from Economic Research Forum. Available from Internet: http://erf.org.eg/wp-content/uploads/2014/08/499.pdf 
Berger, A. N.; Humphrey, D. B. 1997. Efficiency of financial institutions: International survey and directions for future research, European Journal of Operational Research 98(2): 175-212. https://doi.org/10.1016/S0377-2217(96)00342-6

Bos, J. W. B.; Schmiedel, H. 2007. Is there a single frontier in a single European banking market?, Journal of Banking \& Finance 31(7): 2081-2102. https://doi.org/10.1016/j.jbankfin.2006.12.004

Casu, B.; Ferrari, A.; Zhao, T. S. 2013. Regulatory reform and productivity change in Indian banking, Review of Economics and Statistics 95(3): 1066-1077. https://doi.org/10.1162/REST_a_00298

Chambers, R. G.; Chung, Y.; Färe, R. 1996. Benefit and distance function, Journal of Economic Theory 70(2): 407-419. https://doi.org/10.1006/jeth.1996.0096

Chang, T. P.; Hu, J. L.; Chou, R. Y.; Sun, L. 2012. The source of bank productivity growth in China during 2002-2009: a disaggregation view, Journal of Banking \& Finance 36(7): 1997-2006. https://doi.org/10.1016/j.jbankfin.2012.03.003

Chen, K. H.; Yang, H. Y. 2011. A cross-country comparison of productivity growth using the generalised metafrontier Malmquist productivity index: with application to banking industries in Taiwan and China, Journal of Productivity Analysis 35(3): 197-212. https://doi.org/10.1007/s11123-010-0198-7

Drake, L.; Hall, M. J. B.; Simper, R. 2006. The impact of macroeconomic and regulatory factor on bank efficiency: a non-parametric analysis of Hong Kong's banking system, Journal of Banking \& Finance 27(5): 891-917. https://doi.org/10.1016/j.jbankfin.2005.03.022

Duygun, M.; Sena, V.; Shaban, M. 2016. Trademarking activities and total factor productivity: Some evidence for British commercial banks using a metafrontier approach, Journal of Banking \& Finance 72(S): 70-80. https://doi.org/10.1016/j.jbankfin.2016.04.017

Färe, R.; Grosskopf, S.; Norris, M.; Zhang, Z. 1994. Productivity growth, technical progress, and efficiency change in industrialized countries, American Economic Review 84(1): 66-83.

Fu, T.-T.; Juo, J.-C.; Chiang, H.-C.; Yu, M.-M.; Huang, M.-Y. 2016. Risk-based decompositions of the meta profit efficiency of Taiwanese and Chinese banks, Omega 62: 34-46. https://doi.org/10.1016/j.omega.2015.08.007

Fujji, H.; Managi, S.; Matousek, R. 2014. Indian bank efficiency and productivity changes with undesirable outputs: a disaggregated approach, Journal of Banking \& Finance 38(1): 41-50. https://doi.org/10.1016/j.jbankfin.2013.09.022

Hayami, Y. 1969. Sources of agricultural productivity gap among selected countries, American Journal of Agricultural Economics 51(3): 564-575. https://doi.org/10.2307/1237909

Hayami, Y.; Ruttan, V. M. 1970. Agricultural productivity differences among countries, American Economic Review 60(5): 895-911.

Huang, T. H.; Chiang, L. C.; Chen, K. C. 2011. An empirical study of bank efficiencies and technology gaps in European banking, The Manchester School 79(4): 839-860. https://doi.org/10.1111/j.1467-9957.2010.02178.x

Kontolaimou, A.; Kostas, T. 2010. Are cooperatives the weakest link in European banking? A nonparametric metafrontier approach, Journal of Banking \& Finance 34(8): 1946-1957. https://doi.org/10.1016/j.jbankfin.2010.01.003

Kumbhakar, S. C.; Wang, D. 2007. Economic reforms, efficiency and productivity in Chinese banking, Journal of Regulatory Economics 32(2): 105-129. https://doi.org/10.1007/s11149-007-9028-X

Lee, C.-C.; Huang, T.-H. 2017. Cost efficiency and technological gap in Western European banks: a stochastic metafrontier analysis, International Review of Economics \& Finance 48: 161-178. https://doi.org/10.1016/j.iref.2016.12.003

Matthews, K.; Zhang, N. 2010. Bank productivity in China 1997-2007: measurement and convergence, China Economic Review 21(4): 617-628. https://doi.org/10.1016/j.chieco.2010.06.004 
Matthews, K.; Zhang, X.; Guo, J. 2009. Nonperforming loans and productivity in Chinese banks, 19972006, The Chinese Economy 42(2): 30-47. https://doi.org/10.2753/CES1097-1475420202

O'Donnell, C. P.; Rao, D. S. P.; Battese, G. E. 2008. Metafrontier frameworks for the study of firm-level efficiencies and technology ratios, Empirical Economics 34(2): 231-255. https://doi.org/10.1007/s00181-007-0119-4

Oh, D. H.; Lee, J. D. 2010. A metafrontier approach for measuring Malmquist productivity index, Empirical Economics 38(1): 47-64. https://doi.org/10.1007/s00181-009-0255-0

Pasiouras, F. 2008. International evidence on the impact of regulations and supervision on banks' technical efficiency: an application of two-stage data envelopment analysis, Review of Quantitative Finance and Accounting 30(2): 187-223. https://doi.org/10.1007/s11156-007-0046-7

Pastor, J.; Asmild, M.; Lovell, C. A. K. 2011. The biennial Malmquist productivity change index, SocioEconomic Planning Sciences 45(1): 10-15. https://doi.org/10.1016/j.seps.2010.09.001

Pastor, J.; Lovell, C. A. K. 2005. A global Malmquist productivity index, Economics Letters 88(2): 266271. https://doi.org/10.1016/j.econlet.2005.02.013

Portela, M.; Thanassoulis, E. 2010. Malmquist-type indices in the presence of negative data: an application to bank branches, Journal of Banking \& Finance 34(7): 1472-1483. https://doi.org/10.1016/j.jbankfin.2010.01.004

Ray, S. C.; Desli, E. 1997. Productivity growth, technical progress and efficiency change in industrialized countries: comment, American Economic Review 87(5): 1033-1039.

Simar, L.; Wilson, P. 1998. Sensitivity analysis of efficiency scores: how to bootstrap in nonparametric frontier models, Management Science 44(1): 49-61. https://doi.org/10.1287/mnsc.44.1.49

Sufian, F. 2009. The impact of off-balance sheet items on banks' total factor productivity: empirical evidence from the Chinese banking sector, American Journal of Finance and Accounting 1(3): 213-238. https://doi.org/10.1504/AJFA.2009.026482

Tone, K. 2001. A slacks-based measure of efficiency in data envelopment analysis, European Journal of Operational Research 130(3): 498-509. https://doi.org/10.1016/S0377-2217(99)00407-5

Tulkens, H.; Vanden Eeckaut, P. 1995. Non-parametric efficiency, progress and regress measures for panel data: methodological aspects, European Journal of Operational Research 80(3): 474-499. https://doi.org/10.1016/0377-2217(94)00132-V

Zhu, N.; Wang, B.; Wu, Y. R. 2015. Productivity, efficiency, and non-performing loans in the Chinese banking industry, The Social Science Journal 52(4): 468-480.

https://doi.org/10.1016/j.soscij.2014.10.003 